\title{
A Garantia do Direito Social à Assistência Farmacêutica: O Papel do Sistema Jurídico e do Sistema Político
}

\author{
THE GUARANTEE OF THE SOCIAL RIGHT TO PHARMACEUTICAL \\ ASSISTANCE: THE FUNCTION OF THE LEGAL \\ SYSTEM AND THE POLITICIAN SYSTEM
}

Silvia Badim Marques( ${ }^{*}$

\section{RESUMO}

O presente trabalho aborda a relação dos sistemas jurídico e político na garantia do direito social à assistência farmacêutica - a partir da análise de decisões judiciais proferidas em processos, as quais têm por objeto o fornecimento de medicamentos pelo Estado de São Paulo -, bem como o papel desses sistemas na garantia desse direito social. Além disso, analisa as conseqüências jurídicas e políticas dessas decisões judiciais, com base na Teoria Pura do Direito de Hans Kelsen e na Teoria dos Sistemas Autopoiéticos de Niklas Luhmann.

\section{Palavras-chave}

Decisão Judicial; Direito Social à Assistência Farmacêutica; Sistema Jurídico; Sistema Político.

\section{ABSTRACT}

The present work approaches the relation between the legal and the politician systems politician regarding to the guarantee of the social right to the pharmaceutical assistance, from the analysis of judicial decisions that have for subject the medicine supply by the State of São Paulo, as well as the

(") Advogada, mestre em saúde pública pela Universidade de São Paulo. E-maili:<sbadim@usp.br>. Recebido em 23.3.06. Aprovado em 10.5.06. 
role of these systems in the guarantee of this social right. Moreover, it analyzes the legal and politics consequences of these decisions, based on the Pure Theory of Law, from Hans Kelsen, and in the Theory of the Autopoietics System, from Niklas Luhmann.

\section{Key words}

Judicial Decision; Legal System; Political System; Social Right to Pharmaceutical Assistance.

\section{INTRODUÇÃO}

Os direitos sociais, positivados no Estado de direito com o advento dos Estados de bem-estar social, principalmente após as duas grandes guerras mundiais, trazem para o âmago dos Estados modernos uma nova concepção de direitos que, ao contrário dos direitos individuais até então tutelados, não pertencem a um indivíduo, e sim a um grupo social, ou até mesmo a grupos indefinidos de pessoas.

Como salienta Lopes (1), "os novos direitos sociais, espalhados pelo texto constitucional, diferem em natureza dos antigos direitos subjetivos. Não se distinguem apenas por serem coletivos, mas por exigirem remédios distintos. Mais ainda, têm uma implicação política inovadora na medida em que permitem a discussão da justiça geral e distributiva".

Até então, a concepção de Direito estava voltada para a garantia de direitos e liberdades individuais, em face ao poder do Estado que, neste contexto, tinha um papel de abstenção, ou seja, de não interferência frente a esses direitos e liberdades. As políticas públicas não podiam condicioná-los e o Estado não podia intervir em seu âmbito, a não ser para resguardálos, em caso de ameaça ou transgressão.

Assim, o papel do Estado resumia-se ao papel de "polícia", estando vetada a sua intervenção na vida social e econômica das nações, a não ser para garantir - sempre como "polícia" - a segurança, a moralidade pública e a saúde públicas. De acordo com Amara/(2), "os direitos voltados̀ ao valor liberdade foram classificados como negativos, como limites constitucionais ao poder do Estado".

(1) LOPES, J. R. L. Direito subjetivo e direitos sociais: o dilema do judiciário no estado social de direito. In:FARIA, J.E. (Org). Direitos humanos, direitos sociais e justiça. São Paulo: Malheiros Ed., 2002. p. 127.

(2) AMARAL, G. Direitos, escassez \& escolha: em busca de critérios jurídicos para lidar com a escassez de recursos e as decisões trágicas. Rio de Janeiro: Renovar, 2001. p. 56. 
Os direitos sociais, por sua vez, são direitos que, segundo Marshal/(3), referem-se ao elemento social, "a tudo o que vai desde o direito a um mínimo de bem-estar econômico e segurança ao direito de participar, por completo, na herança social e a levar a vida de um ser civilizado de acordo com os padrões que prevalecem na sociedade". E, nesse contexto, o Estado possui uma função estratégica, qual seja: passa a exercer um papel mais amplo na vida social, empregando seu poder "supremo e coercitivo para suavizar, por uma intervenção decidida, algumas das conseqüências mais penosas da desigualdade econômica"(4).

Assim, para garantir a efetivação dos direitos sociais, o Estado passa a intervir mais na vida da sociedade, como realizador de políticas sociais e econômicas e como prestador de serviços públicos. Como bem observa Faria(5), "ao contrário da maioria dos direitos individuais tradicionais, cuja proteção exige apenas que o Estado jamais permita sua violação, os direitos sociais são podem simplesmente ser atribuídos aos cidadãos; cada vez mais elevados à condição de direitos constitucionais, os direitos sociais requerem do Estado um amplo rol de políticas públicas dirigidas a segmentos específicos da sociedade - políticas essas que têm por objetivo fundamentar esses direitos e atender às expectativas por eles geradas com sua positivação".

Percebe-se, desta forma, que há uma nítida vinculação entre os direitos sociais e as políticas sociais, que garantem de fato estes direitos e, esta relação diferencia-se da até então estabelecida, entre o direito e a política para a garantia dos direitos individuais, focada na contenção do poder do Estado e na garantia das liberdades individuais. Direito e política passam a se relacionar não apenas para conter o poder do Estado; mas, também, para ordenar a vida social e econômica das nações ${ }^{(6)}$.

Assim, a proteção e a garantia desses direitos requerem uma atuação ativa tanto do sistema jurídico, como do sistema político, de acordo com as funções exercidas por cada um desses sistemas na sociedade.

De acordo com Amara/(7), "a efetividade dos direitos positivos (...) demanda a existência de um aparato estatal da prestação, incluindo estru-

(3) MARSHALL, T. H. Cidadania, classe social e status. Rio de Janeiro: Zahar, 1967. p. 64.

(4) DALLARI, D. A. Elementos de teoria geral do Estado. 23. ed. São Paulo: Saraiva, 2002. p. 279.

(5) FARIA, J. E. O Judiciário e os direitos humanos e sociais: notas para uma avaliação da justiça brasileira. In: (Org.). Direitos humanos, direitos sociais e justiça. São Paulo: Malheiros Ed., 2002. p. 94-112.p. 105.

(6) Kuntz, R. Estado, mercado e direitos. In: FARIA, J.E.; KUNTZ, R. Qual o futuro dos direitos? Estado, mercado e justiça na reestruturação capitalista. São Paulo: Max Limonad, 2002. Kuntz salienta que, em relação aos direitos sociais, "O poder público é concebido, neste quadro, como responsável pela equalização de oportunidades, pelo equilíbrio do jogo de mercado, pela manutenção da prosperidade e pela administração de uma rede social de segurança" (p. 34).

(7) AMARAL, G. Interpretação dos direitos fundamentais e o conflito entre poderes. In:TORRES, R. L (Org.). Teoria dos direitos fundamentais. 2. ed. Rio de Janeiro: Renovar, 2001. p. 111. 
tura física, logística e pessoal, a gerar gastos que devem ser cobertos". Assim, a garantia efetiva de um direito social depende, necessariamente, da estrutura política de atuação do Estado. Temos, portanto, que a garantia de um direito social vai depender simultaneamente de operações e valores contidos no sistema jurídico e no sistema político.

Os direitos sociais, instituídos no ordenamento jurídico brasileiro pela Constituição Federal de 1988, trazem para o âmbito de nosso sistema jurídico, portanto, uma nova concepção de direitos, com implicações para o funcionamento dos sistema jurídico e político e para a relação entre eles.

No que concerne ao direito social à saúde, tema que nos interessa para o desenvolvimento deste trabalho, o sistema jurídico e o sistema político possuem funções distintas e fundamentais para a sua garantia. Como esse direito depende, para a sua concretude, da elaboração de políticas públicas e da prestação de um serviço público de saúde para toda a coletividade, conseqüentemente, depende também de uma atuação positiva do Estado e do sistema político para a sua garantia.

Neste contexto, buscaremos analisar de que forma esses sistemas se relacionam na garantia dos direitos sociais, especificamente do direito social à assistência farmacêutica, a partir da análise de decisões judiciais em ações que têm por objeto o fornecimento de medicamentos e insumos por parte do Estado. Tomaremos como referência, para essa análise, a Teoria dos Sistemas Autopoiéticos, de Niklas Luhmann, contrapondo-a à Teoria Pura do Direito, de Hans Kelsen.

\section{POSITIVISMO JURIDICO: O PURISMO METODOLOGICO}

O positivismo jurídico, como nos demonstra a Teoria Pura do Direito, de $\mathrm{Kelsen}{ }^{(8)}$, não se considera obrigado senão a conceber o direito de acordo com sua própria estrutura, ou seja, de acordo com as operações próprias de seu sistema operativo: o sistema normativo. Segundo Azevedo(9) "seguindo uma inclinação científica geral, peculiar ao mundo moderno, em especial ao século XIX, o positivismo jurídico traduz a possibilidade de estudar o Direito e aplicá-lo independentemente de valorações éticas e de suas implicações sociais".

Desta forma, a teoria do Direito na modernidade ergue-se sobre os fundamentos da racionalidade, típicos da ciência moderna, que pregam o purismo metodológico e a construção lógica do ordenamento jurídico, com base apenas no próprio ordenamento jurídico. A Teoria Pura do Direito

(8) KELSEN, H. Teoria pura do direito. 6. ed. São Paulo: Martins Fontes, 1998.

(9) AZEVEDO, P. F. Direito, justiça social e neoliberalismo. São Paulo: Ed. Revista dos Tribunais, 2000. p. 14. 
afasta, do Direito e da ciência jurídica, quaisquer elementos que não os normativos decorrentes do arcabouço de leis e normas que regem o Estado. Somente assim, sustentam os positivistas, é possivel a concepção de uma teoria do Direito efetivamente autônoma.

Para Kelsen, só são considerados objetos do conhecimento jurídico as relações jurídicas, ou seja, aquelas constituídas através de normas jurídicas. Nas palavras de Kelsen(10): "A ciência jurídica procura apreender o seu objeto juridicamente, isto é, do ponto de vista do Direito. Apreender algo juridicamente não pode, porém, significar senão apreender algo como direito, o que quer dizer: como norma jurídica ou conteúdo de uma norma jurídica, como determinado através de uma forma jurídica."

A ciência jurídica irá se voltar, portanto, para a apreensão do Direito como norma jurídica, como conteúdo de uma norma jurídica, ou como determinado através de uma forma jurídica. $E$, não havendo direito senão o direito estatal, emanado do Estado, a metodologia jurídica funda-se sobre paradigmas lógico-dedutivos, ou seja, sobre a dedução lógica das normas postas validamente pelo Estado.

Uma das principais características do Direito positivo, segundo Ke/sen, é a do próprio Direito regular a sua produção e aplicação. Assim, temos, de acordo com o purismo metodológico, uma teoria estática e úma teoria dinâmica do Direito. "A primeira tem por objeto o Direito como um sistema de normas em vigor, o Direito em seu momento estático; a outra tem por objeto o processo jurídico em que o Direito é produzido e aplicado, o Direito no seu movimento. Deve, no entanto, observar-se, a propósito, que este mesmo processo é, por sua vez, regulado pelo Direito."(11)

Para os fins a que se propõe este trabalho, ou seja, a análise da relação entre o sistema jurídico e o sistema político na garantia dos direitos sociais, daremos enfoque à dinâmica jurídica, à produção e aplicação desses direitos pelo Poder Judiciário.

A ordem jurídica tem seu fundamento, para a Teoria Pura do Direito, na Constituição Federal. É a Constituição Federal a norma fundamental, a base de todo o ordenamento jurídico do Estado, da qual decorrem as demais normas jurídicas. Uma norma jurídica só será válida e, portanto, aceita pelo ordenamento jurídico estadual, se produzida segundo as regras fixadas na norma fundamental.

Desta forma, é a Constituição Federal o fundamento comum de todo o ordenamento jurídico. E esta é uma Constituição determinada, efetivamente estabelecida. Para Kelsen ${ }^{(12)}$, todas as normas do ordenamento jurídico são

(10) KELSEN, H. op. cit., p. 79.

(11) Id. Ibid., p. 80.

(12) Id. Ibid. 
normas postas a partir da Constituição. E por ser a matriz das normas postas, da qual decorre todo o ordenamento jurídico, a norma fundamental não pode ser considerada uma norma posta e sim uma norma pressuposta. $E$, na pressuposição desta norma fundamental, não é afirmado qualquer valor transcendente ao Direito positivo(13). A norma será considerada fundamental, desta forma, se a sua validade objetiva já não pode ser posta em questão.

Temos, portanto, que, para a Teoria Pura do Direito, a Constituição Federal desempenha um papel fundamental na validação e unidade do sistema jurídico e é nela que encontramos as diretrizes e os princípios que norteiam toda a produção normativa $e$, conseqüentemente, onde encontramos o fundamento para todas as operações do sistema jurídico.

Dentro da dinâmica jurídica, da criação do Direito a partir do próprio Direito, destaca-se que a teoria pura concebe a decisão judicial não apenas como mera declaradora de direitos já estatuídos pela legislação e pelo ordenamento jurídico-positivo; mas, reconhece o caráter criador e constitutivo de direitos desta decisão, que são instituídos apenas para as partes litigantes $^{(14)}$. E, assim, a decisão judicial será regulada pela Constituição Federal e pelas leis que the seguem. A função do Poder Judiciário, neste contexto, é averiguar as questões de fato e de direito constantes de um processo judicial e, posteriormente, "ordenar in concreto a sanção estatuída in abstracto pela norma jurídica geral. Estas averiguações e esta ordem ou comando são as funções essenciais da decisão judicial"(15).

Sob esse paradigma positivista, delineado pela teoria de Kelsen, solidifica-se o sistema jurídico na modernidade. De acordo com Azevedo(16), "O desígnio de Kelsen foi o de libertar a ciência do direito de todos os elementos que the fossem estranhos, evitando um sincretismo metodológico, que lhe obscurecesse a essência e diluísse os limites que the são impostos". Todavia, a mecanização da aplicação do direito e seu cientificismo rigorosamente lógico-positivista, em contrapartida, afastaram o direito da complexidade das questões de nosso tempo ${ }^{(17)}$.

(13) COMPARATO, F.K. Fundamento dos direitos humanos. In:MARCÍLIO, M. L., PUSSOLI, L. Cultura dos direitos humanos. São Paulo: $L T r$, 1998. p. 51-74.p. 51-74. Comparatoressalta que, para a "teoria positivista, o fundamento do Direito não é transcendental ao homem e à sociedade, mas se encontra no pressuposto lógico (o contrato social ou a norma fundamental) de que as leis são válidas e devem ser obedecidas, quando forem editadas segundo um processo regular (isto é, organizado por regras aceitas pela comunidade) e pela autoridade competente, legitimada de acordo com princípios também anteriormente estabelecidos e aceitos. É a explicação formal da validade do direito" (p. 58).

(14) De acordo com Kelsen, op. cit., "a decisão judicial também pode ser considerada como fonte dos deveres e dos direitos das partes litigantes por ela estatuídos, ou da atribuição de competência ao órgão que tem de executar esta decisão" (p. 259).

(15) KELSEN, H. op. cit., p. 264.

(16) AZEVEDO, P. F. op. cit., p. 20.

(17) DALLARI, D. A. O poder dos juízes. 2. ed. São Paulo: Saraiva, 2002. Segundo Dallari, "pretendendo "purificar" o pensamento jurídico e livrá-lo das antigas especulações filosóficas abstratas, bem como da influência até então crescente da sociologia, Kelsen construiu uma teoria pura do direito, ou teoria normativa, que afastou os fundamentos filosóficos, sociais e reduziu o direito a uma simples forma, que aceita qualquer conteúdo" (p. 85). 
Acrescentamos, a esta consideração de Azevedo, o afastamento também de fundamentos políticos da ciência do Direito. A ciência do direito, portanto, aperfeiçoa-se dentro do paradigma positivista, criando um sistema jurídico funcionalmente estável; mas, fechado a quaisquer outros elementos que não provenientes estritamente do arcabouço legal.

\section{SISTEMA JURIDICO, SISTEMA POLÍTICO: AS RELAÇOESS INEVITAVEIS}

Para o positivismo jurídico, como já citado, a Constituição Federal é tomada de forma objetiva, ou seja, representa o fundamento da ordem jurídica estadual. No entanto, essa mesma Constituição Federal, para a contradição do purismo metodológico, não pode ser apartada de sua dimensão política. Segundo Dallari (18), "a Constituição é um documento político que transforma em lei os objetivos da sociedade, inclusive organizando-a para alcançá-los".

O próprio Kelsen, ao explicar a Constituição Federal como norma pressuposta, coloca em evidência a sua afirmação de que "como organização política, o Estado é uma ordem jurídica" (19). A norma fundamental não pode ser considerada uma norma posta pelo positivismo jurídico, visto que a fundamentação de validade de uma norma objetiva, só pode ser uma outra norma. E a norma fundamental é exatamente a norma mais alta do escalão de produção do Direito, da qual decorrem todas as outras normas. Assim, não pode ser obtida através de uma dedução lógico-formal das normas postas.

Para Dallari (20), "A explicação de Kelsen (...) baseia-se numa norma fundamental hipotética, cujo caráter jurídico só pode ser suposto, uma vez que não foi posta por ninguém. Esta base é de evidente fragilidade, resultando insustentável a afirmação de que o poder do Estado é total e exclusivamente jurídico". Assim, ao caracterizar-se como um documento não só jurídico, mas, também, político, a Constituição Federal representa um ponto de convergência inevitável entre os sistemas político e jurídico de um Estado.

O próprio Estado Moderno, ao ser instituído, no final do século XVIII, sobre o paradigma da estrita legalidade, do governo "do povo para o povo" e da proteção das liberdades individuais, visava controlar, através da lei, o exercício do poder político do Estado, realçando a interdependência entre o sistema jurídico e político(21).

(18) DALLARI, S. G. Os estados brasileiros e o direito à saúde. São Paulo: Hucitec, 1995. p. 26.

(19) KELSEN, H. op. cit., p. 317.

(20) DALLARI, D. A. Elementos de teoria geral do Estado, cit., p. 112-113.

(21) COELHO, P. M. C. Controle jurisdicional da administração pública. São Paulo: Saraiva, 2002. 
Percebemos que, ao determinar juridicamente a forma de governo, o modo de aquisição e exercício do poder político do Estado, a Constituição Federal também está determinando as matrizes de funcionamento do sistema político. Balizado pela lei pressuposta, o sistema político irá dialogar constantemente com o sistema jurídico, pois uma vez constituídos os poderes do Estado, estes irão movimentar também o próprio Direito, impulsionando sua dinâmica jurídica de criação e aplicação. E, segundo Dallari ${ }^{(22)}$, isso implica, necessariamente, num "entrelaçamento de situações, de relações, de justificativas, de objetivos, que compreende aspectos jurídicos, mas que contém, ao mesmo tempo, um indissociável conteúdo político".

Desta forma, percebemos que, afastada a concepção extremamente positivista do Direito - que por opção metodológica apartou o Direito e o sistema normativo de quaisquer relações que pudessem travar com outros sistemas - , aparecem as relações existentes entre o Direito/sistema normativo e os demais sistemas sociais e campos do conhecimento ${ }^{(23)}$. Nas palavras de Azevedo: "afastada a ideologia da separação, libera-se a Ciência do Direito do leito de Procusto, em que a confinou o positivismo. Emergem os interesses a que se ligam as normas." (24)

Assim, percebemos que o sistema jurídico e o sistema político possuem uma nítida e inevitável relação ainda mais estreitada pelas peculiaridades dos direitos sociais. Isto porque os direitos sociais dependem de uma atuação positiva do Estado para serem implementados, através da elaboração e implementação de políticas públicas, bem como da aplicação de recursos públicos e da prestação de serviços públicos. $E$, assim, para a compreensão e aplicação dos direitos sociais, que são intrinsecamente permeados por questões políticas e sociais, faz-se necessário que o Direito conheça, dentro dos seus limites operacionais, essas questões que the são pertinentes.

\section{O SISTEMA JURIDICO E O SISTEMA POLÍTICO NA PERSPECTIVA DA TEORIA DOS SISTEMAS AUTOPOIETICOS DE NIKLAS LUHMANN}

Para identificarmos as relações entre sistema jurídico e sistema político na garantia dos direitos sociais, especificamente do direito social à saúde, partiremos do referencial teórico de Niklas Luhmann, e sua teoria dos sistemas autopoiéticos.

(22) DALLARI, D. A. Elementos de teoria geral do Estado, cit., p.127.

(23) DIÁZ, E. Sociologia y filosofia de/ derecho. Madrid: Tauru, 1976. Díaz salienta que não se entende plenamente o mundo jurídico se o sistema normativo se insula e se separa da realidade em que nasce e à qual se aplica, bem como do sistema de legitimidade que o inspira e possibilita sua própria crítica racional.

(24) AZEVEDO, P. F. op. cit., p. 30. 
Luhmann parte da assertiva de que a sociedade sempre foi uma rede de comunicações: a operação característica da sociedade é a comunicação. E essa rede evoluiu através do tempo, de forma concomitante à evolução social - entendendo-se aqui evolução social como o "resultado de um processo constante de variação, seleção e estabilização de estruturas"(25) e não como "progresso". E, de acordo com este autor, a evolução social, enquanto fenômeno de variação, seleção e reestabilização das estruturas, é entendida através da noção de diferenciação social. Evolui a sociedade e, portanto, as formas de comunicação, de acordo com as formas de diferenciação social que são estabilizadas ${ }^{(26)}$.

Nas sociedades modernas, segundo Luhmann, a diferenciação social estabilizou-se em torno de critérios funcionais, com a formação de subsistemas sociais especializados funcionalmente, como os sistemas político, jurídico e econômico. Tomando como marco da modernidade a consolidação dos Estados modernos de direito no final do século XVIII, a evolução social estabiliza como critério de diferenciação social os sistemas diferenciados funcionalmente. Assim, solidificam-se distintos subsistemas sociais dentro da sociedade, como o sistema jurídico, o sistema político e o sistema econômico, com funções específicas, autonomia funcional e códigos de comunicação próprios.

Esses subsistemas sociais, de acordo com Luhmann, produzem uma comunicação específica, ao cumprirem as suas funções específicas dentro da sociedade. E, assim, conferem unidade ao sistema social. Cada sistema parcial, desta forma, possui "seu próprio código (esquema binário que caracteriza a comunicação do sistema), suas operações específicas de reprodução, ou seja, sua clausura operativa (o fechamento operativo) e sua abertura ao ambiente"(27).

Para se alcançar a unidade do sistema social, um sistema não pode operar com base no código de comunicação de outro sistema. E também não pode produzir sua comunicação própria, a não ser através de suas operações internas, perseguindo os exatos fins almejados pelo sistema. Temos, portanto, que cada sistema diferenciado funcionalmente opera com um código de comunicação próprio, com base em operações também próprias e visando um determinado fim.

(25) CAMPILONGO, C. F. Política, sistema jurídico e decisão judicial. São Paulo: Max Limonad, 2002. p. 23. (26) Para Luhmann, nas sociedades ditas primitivas, a comunicação e a sociedade estiveram organizadas em torno de critérios de diferenciação social "naturais", como por exemplo, gênero e idade. Nas sociedades antigas, a diferenciação social se estabilizou em torno de critérios geográficos, por exemplo, campo/cidade, como nas cidades-estado da Grécia clássica. Nas sociedades medievais, por sua vez, essa diferenciação se estabilizou em torno de critérios hierárquicos, como os plebeus/nobres, cidadãos/ escravos do "antigo regime". Já nas sociedades modernas, a diferenciação social estabilizou-se em torno de critérios funcionais, com a formação de subsistemas sociais especializados funcionalmente, como o sistema político, jurídico e econômico.

(27) CAMPILONGO, C. F. op. cit., p. 66. 
Como salienta Mathis, "os sistemas operam fechados, no sentido de que as operações que produzem os novos elementos do sistema, dependem das operações anteriores do mesmo sistema e são, ao mesmo tempo, as condições para futuras operações. Esse fechamento é a base da autonomia do sistema. Ou, em outras palavras, nenhum sistema pode atuar fora das suas fronteiras"(28). É essa clausura operativa, portanto, que possibilita, ao mesmo tempo a autonomia de cada subsistema social e a sua abertura cognitiva do sistema para os estímulos provenientes do ambiente.

Destaca-se que, para Luhmann, a clausura operativa dos sistemas sociais não significa que esses sistemas se fecham para a complexidade das questões e problemas do mundo contemporâneo. Ao contrário, é através do fechamento operacional dos sistemas parciais, que Luhmann enfrenta a complexidade ${ }^{(29)}$.

Com base nesses preceitos, ergue-se o conceito de sistema autopoiético na teoria dos sistemas de Luhmann. Nas palavras de Campilongo entende-se por autopoiético um sistema que "não possui correspondente funcional no ambiente"(30). Ou, ainda, na definição de Mathis, significa "que um sistema complexo reproduz os seus elementos e suas estruturas dentro de um processo operacionalmente fechado com ajuda de seus próprios elementos"(31).

Assim, entendendo a complexidade como a oferta contínua de possibilidades, como "o conjunto de possíveis estados e acontecimentos de um sistema"(32), Luhmann reconhece a complexidade das questões de nosso tempo, trazendo-a para o interior dos sistemas sociais. Destaca-se que a noção de complexidade, para Luhmann, encontra-se atrelada à noção de contingência. Contingência, "nas palavras de Luhmann, é algo que não é necessário nem impossível, algo então que é (era ou será) assim como é mas também poderia ser diferente"(33).

Um sistema social, portanto, reage sempre aos estímulos do ambiente e dos demais sistemas com sua freqüência interna, oferecendo-Ihes resposta a partir de seu código de comunicação próprio e dentro de seus limites

(28) MATHIS, A. O conceito de sociedade na teoria dos sistemas de Niklas Luhmann. Rebea 2002 [texto doutrina]; [18 screens]. p. 3. Disponivel em: <www.rebea.org.br/rebea/arquivos/niklas.pdf>. Acesso em: 30.jan.2005.

(29) NEVES, M. C. P. Entre Têmis e Leviatã: uma relação difícil. 1997. Tese (Titular do Departamento de Filosofia e Teoria Geral do Direito) - Faculdade de Direito da Universidade de São Paulo, São Paulo, 1997. Segundo Neves, "com pretensão de um modelo explicativo mais abrangente a respeito da emergência da sociedade moderna, Luhmannutiliza, em primeiro lugar, o critério da complexidade, entendida como presença permanente de mais possibilidades (alternativas) do que as que são suscetiveis de ser atualizadas" (p. 19).

(30) CAMPILONGO, C. F. op. cit., p. 22.

(31) MATHIS, A. op. cit., p. 3.

(32) Id. Ibid., p. 5.

(33) Id., loc. cit. 
estruturais. "Isso impõe limites claros às funções e prestações de cada sistema funcional e permite identificar fronteiras e mecanismos de interdependência com os demais sistemas." ${ }^{(34)}$

\section{O SISTEMA JURÍDICO E A FUNÇÃO DO PODER JUDICIÁRIO}

Para Luhmann, a principal função do Direito é a de promover a "generalização congruente de expectativas normativas". Ou seja, o direito reduz e mantém a complexidade social, através do fechamento de seu sistema operativo, para promover a generalização congruente de expectativas normativas ${ }^{(35)}$.

Assim, somente as expectativas generalizadas de modo congruente pelo sistema jurídico gozam da segurança e proeminência das expectativas normativas jurídicas. Desta forma, Luhmann, 1983, especifica que a principal função do Direito, em um mundo altamente complexo e contingente, é a generalização congruente de expectativas normativas. $O$ código próprio do sistema jurídico é traduzido no binário direito/não direito (ou lícito/ilícito). Os programas do sistema jurídico, por sua vez, estão contidos nos textos das leis, nas jurisprudências, nos contratos, entre outros e implementam o valor direito/não direito.

E, como já salientado, nenhum outro sistema pode operar com base nesse código e nestes programas, senão o sistema jurídico. De acordo com Campilongo "o direito positivo não entende outras razões além daquelas traduzíveis nos termos de seu código, programas e função"(36). Portanto, é através da implementação do valor contido no código do direito (direito/não direito) por seus programas específicos, que o sistema jurídico poderá, exclusivamente, oferecer respostas claras e precisas aos conflitos ocorridos dentro e fora do sistema e, assim, garantir as expectativas normativas.

E, nesse contexto, ainda de acordo com Campilongo, a função da Justiça seria "a consistência das operações internas que reconhecem e qualificam os interesses como protegidos ou repelidos pelo direito"(37). A operação realizada pelos Tribunais de Direito é considerada por Luhmann como aquela que condiciona o fechamento operativo do sistema jurídico. E, também, é através da função judicial que o sistema jurídico se abre cognitivamente ao

(34) CAMPILONGO, C. F. op. cit., p. 75.

(35) LUHMANN, N. Sociologia do direito I. Rio de Janeiro: Tempo Brasileiro; 1983. Nas palavras do próprio Luhmann, "o comportamento social em um mundo altamente complexo e contingente exige a realização de reduções que possibilitem expectativas comportamentais recíprocas e que são orientadas a partir das expectativas sobre tais expectativas. Na dimensão temporal essas estruturas de expectativas podem ser estabilizadas através da normatização" (p. 109).

(36) CAMPILONGO, C. F. op. cit., p. 22.

(37) Id. Ibid., p. 78. 
ambiente. A jurisdição, portanto, representa a garantia de resposta do sistema jurídico a todas as questões, advindas da sociedade, relacionadas ao valor contido no binário direito/não direito, sendo os Tribunais o órgão central do sistema jurídico.

Como garantia do fechamento operativo do sistema jurídico, e como garantia de que esse sistema estará aberto cognitivamente para as demandas internas e externas (relativas a conflitos gerados em torno do valor direito/não direito), o Judiciário deve sempre proferir uma decisão em torno desses conflitos $^{(38)}$.

\section{O SISTEMA POLÍTICO}

Segundo Azevedo, "o conceito de política está estritamente ligado ao de poder, pertencendo à categoria de poder do homem sobre outro homem, exprimindo-se esta relação de variada forma na linguagem política como relação entre governantes e governados, entre soberano e súditos, entre Estado e cidadãos, entre autoridade e obediência etc."(39).

Luhmann também reconhece que o conceito de política está intrinsecamente ligado ao uso do poder. Desta forma, estabelece que o sistema político, com base no uso do poder que lhe é característico, tem por função precípua tomar decisões coletivamente vinculantes. Reconhece, também, que a linguagem da política é expressa através da relação entre governantes e governados; o código de comunicação específico do sistema político, para a teoria dos sistemas autopoiéticos, está ligado à diferenciação hierárquica das relações de poder, ao binário governo/oposição (ou superior/inferior).

E, para Luhmann, o centro do sistema político é composto pelo Estado. Ou seja, o espaço da tomada das decisões coletivamente vinculantes na modernidade é o Estado. É o Estado que vai desempenhar o papel organizativo central do sistema político, identificando as operações capazes de resgatar a capacidade decisória deste sistema. De acordo com Neves, "O sistema político reproduz-se, primariamente, de acordo com o código de preferência generalizado "poder superior/inferior" (hoje expresso na diferença entre governo e oposição e os seus respectivos programas, estabelecidos por procedimentos eleitorais, parlamentares, burocráticos etc.)"(40).

Como destaca Campilongo, "variação, seleção e estabilização de decisões coletivamente vinculantes - num processo de contínua circulação

(38) Uma vez demandado, o Judiciário não pode escolher entre proferir ou não uma decisão. Dentro dos limites estruturais do sistema jurídico e dentro do valor do Direito, o juiz não pode proferir o non liquet, deve sempre proferir uma decisão, como garantia do fechamento operativo do sistema $\theta$ de sua abertura cognitiva para o ambiente.

(39) AZEVEDO, P. F. op. cit., p. 38.

(40) NEVES, M. C. P. op. cit., p. 112. 
das possibilidades de alternativas de decisão - representam o esforço do sistema político para, operando autonomamente e com base nas suas próprias estruturas, reduzir e manter a complexidade. A cada decisão correspondem novas alternativas e demandas por outras decisões. A função do sistema político democrático é justamente manter esse processo"(41). O sistema político, então, operando autonomamente e com base em seu próprio código de comunicação, pode se abrir cognitivamente ao ambiente. E, desta forma, é capaz de reduzir e manter a complexidade, garantindo sempre que, a cada decisão coletivamente vinculante, correspondam novas possibilidades diferentes de decisão.

Assim, especificadas as funções, programas e códigos de comunicação dos sistemas jurídico e político, bem como a importância da reprodução autopoiética desses sistemas para a manutenção da complexidade e da própria democracia, passaremos a analisar de que forma estes sistemas se relacionam, na perspectiva da teoria dos sistemas.

\section{ACOPLAMENTO ESTRUTURAL ENTRE OS SISTEMAS JURIDICO E POLITICO E OS DIREITOS SOCIAIS}

Campilongo(42), ao falar da abertura cognitiva do sistema jurídico, ressalta que se revela "equivocado, por exemplo, imaginar que a autonomia do sistema jurídico signifique seu isolamento completo em relação ao sistema político. Um sistema auto-referencial não é um sistema que vive independentemente do ambiente. Por isso, os contatos e a exposição do sistema jurídico ao sistema político, e vice-versa, são inerentes à ordem diferenciada funcionalmente".

Entre Direito e política há uma inevitável interdependência, ou, na terminologia de Luhmann, uma situação de "dupla interdependência" entre os sistemas. Apesar da diferenciação existente entre ambos, existem pontos de contato que fazem com que estes sistemas se relacionem intimamente: atuam de forma estritamente ligada à legislação estatal, têm seus princípios decorrentes da mesma fonte (a Constituição Federal), e dependem de um aparato coercitivo para a concretização de suas decisões. $E$, nessa interação, um sistema presta ao outro importantes contribuições, para o desempenho de suas funções específicas ${ }^{(43)}$.

Segundo Campilongo "o sistema político fornece ao sistema jurídico prestações fundamentais, vale dizer, as premissas decisórias (leis) e 0 reforço da eficácia das decisões jurídicas (polícia, prisões, enfim, os meios

(41) CAMPILONGO, C. F. op. cit., p. 72.

(42) Id. Ibid., p. 167.

(43) NEVES, M. C. P. op. cit. 
coercitivos). Igualmente relevantes são as prestações dadas no sentido inverso, isto é, do sistema jurídico ao sistema político, na forma de legitimação das decisões políticas (aplicação de leis) e de oferecimento das premissas para o uso da violência (regulação jurídica do monopólio estatal da força)"(44) (45).

Os direitos sociais, como já salientado, representam uma nova concepção de direitos dentro do sistema jurídico, que dependem de uma atuação positiva do Estado para sua implementação. Ou seja, dependem de estímulos políticos para serem garantidos de fato, para toda coletividade. Desta forma, aproximam ainda mais os sistemas jurídico e político.

Como destaca Lopes, "os direitos coletivos, se atentarmos bem para a sua lista, têm outro caráter. Não se trata, na maioria dos casos previstos no art. $6^{\circ}$, de se conservar uma situação de fato existente (...). Trata-se de situações que precisam ser criadas"(46). Assim, precisam ser criadas condições para a efetivação dos direitos sociais. Isso condiciona, portanto, a garantia do direito social à elaboração de uma política pública e à prestação de um serviço público pelo Estado. Ou seja, condiciona a garantia do direito social à tomada de decisões coletivamente vinculantes, função a ser desempenhada pelo sistema político.

Lopes prossegue com a seguinte indagação: "o direito à educação é mais do que o direito de não ser excluido de uma escola; é, de fato, o interesse em se conseguir uma vaga e as condições para estudar (ou seja, tempo livre, material escolar etc.). Ora, se a vaga não existe, se não existe o tempo livre, se não há material escolar a baixo custo, como garantir juridicamente tal direito? Como transformá-lo de um direito à não interferência (permissão, dever de abstenção) em um direito à prestação (dever de fazer, obrigação) de alguém?"(47). A indagação é pertinente para a análise da proteção jurídica aos direitos sociais, os quais diferem dos direitos subjetivos pela sua própria natureza, e, assim, exigem remédios distintos para a sua garantia(48).

A resposta à indagação: "quais as ações que asseguram, garantem e viabilizam os tais direitos sociais?"(49), não pode ser encontrada através da

(44) CAMPILONGO, C. F. O direito na sociedade complexa. São Paulo: Max Limonad, 2000. p. 82.

(45) Id. Política, sistema jurídico e decisão judicial, cit., destaca que a relação entre direito e política é uma relação de inclusão e exclusão "de recíprocas irritações, de conexões simultâneas (não causais) e analógicas entre os sistemas, enfim de reprodução da diferenciação entre essas duas esferas funcionais" (p. 93).

(46) LOPES, J. R. L. op. cit., p. 126-127.

(47) Id. Ibid., p. 127.

(48) Sustenta-se neste trabalho que os direitos sociais não podem ser tutelados pelo sistema jurídico da mesma forma que os direitos individuais. A eles, não basta o pressuposto básico dos diretos individuais de que "a todo direito corresponde um dever reflexo e uma ação que o assegura", dedutivel com facilidade das normas postas.

(49) LOPES, J. R. L. op. cit., p. 113. 
metodologia lógico-dedutiva do positivismo jurídico, ainda dominante e condutora de nosso sistema jurídico. É preciso ir além do purismo metodológico para que se encontre uma resposta a esta questão. De acordo com Lopes, "a resposta a esta indagação ultrapassa a análise pura e simples do texto legal, ou dos textos legais, supera a exegese e a filologia jurídicas"(50).

É preciso que se reconheça, para alcançar esta resposta, a inevitável relação de interdependência do direito com a política na garantia dos direitos sociais. É preciso, portanto, que o sistema jurídico receba do sistema político os estímulos necessários para a elaboração de uma resposta jurídica, condizente com a natureza das questões que envolvem a efetivação dos direitos sociais. O sistema jurídico só poderá oferecer uma resposta aos conflitos que envolvem os direitos sociais, de acordo com seu código de comunicação próprio, caso processe internamente as referências políticas constantes de uma política pública, formalmente elaborada para garantir eficácia aos direitos sociais.

Bucci sustenta que "adotar a concepção das políticas públicas em direito consiste em aceitar um maior grau de interpenetração entre as esferas jurídica e política ou, em outras palavras, assumir a comunicação que há entre os dois subsistemas, reconhecendo e tornando públicos os processos dessa comunicação (...) $E$ isso ocorre seja atribuindo-se ao direito critérios de qualificação jurídica das decisões políticas, seja adotando-se no direito uma postura crescentemente substantiva e, portanto, mais informada por elementos da política"(51).

Assim, a tutela dos direitos sociais pelo sistema jurídico precisa ser informada dos elementos políticos que lhes são correspondentes, visto a interdependência destes dois sistemas na garantia dos direitos sociais. Todavia, para que o sistema jurídico seja capaz de processar internamente os elementos políticos que envolvem um direito social, é preciso que estes elementos sejam expressos através de uma forma jurídica, reconhecível pelo Direito. Ou seja, é preciso que estes elementos políticos sejam dotados de uma qualificação jurídica, para assim serem "lidos" e processados autopoieticamente pelo sistema jurídico.

Desta forma, de acordo com a teoria dos sistemas, é fundamental que o sistema jurídico se abra ao ambiente e receba, do sistema político, os estímulos necessários para a garantia dos direitos sociais. E para que esses estímulos sejam processados internamente pelo sistema jurídico, é fundamental que eles sejam dotados, também, de uma qualificação jurídica ${ }^{(52)}$.

(50) ld., loc. cit.

(51) BUCCI, M. P. D. Direito administrativo e políticas públicas. São Paulo: Saraiva, 2002. p. 241-242.

(52) Neste contexto a indagação de Bucci, op. cit., é pertinente: "numa época em que o universo jurídico se alarga - em que os direitos sociais e transindividuais deixam de ser meras declarações retóricas e passam a ser direitos positivados em constituições e leis, em busca de efetividade -, não seriam as políticas públicas um foco de interesse juridicamente pertinente, como esquema de agregação de interesses e institucionalização de conflitos?" (p. 241). 
Todavia, a exteriorização da política pública está muito distante de um padrão jurídico uniforme e claramente apreensível pelo sistema jurídico. As políticas públicas são expressas de diversos modos, sem um padrão jurídico claro e definido. Normalmente, são o resultado de uma criação legislativa, complementada através da edição de atos administrativos, nas suas mais variadas formas.

Ainda, segundo Bucci "o modelo das políticas públicas, concebido como forma de implementação do Estado de bem-estar, pairou acima ou ao lado das estruturas jurídicas tradicionais, não tendo sido completamente integrado ao ordenamento jurídico"(53). Assim, revela-se de suma importância, para a manutenção do equilíbrio social, que o Direito se informe de elementos políticos ao garantir um direito social, estando atento para as diferentes formas jurídicas sob as quais as políticas públicas são exteriorizadas e formalizadas.

É preciso, portanto, que o sistema jurídico, dentro de sua clausura operativa, seja capaz de reconhecer e receber os estímulos formalmente emanados do sistema político para a garantia de um direito social. O que gera dificuldades para um sistema "puro", informado apenas pelo próprio Direito.

Daí, a constatação de Faria: "os direitos sociais vêm dificultando a rotina da aplicação da lei"(54). O Poder Judiciário, órgão central do sistema jurídico, como já visto, não pode proferir o non liquet, como garantia do fechamento operativo do Direito. Assim, uma vez provocado, o Poder Judiciário encontra-se obrigado a proferir uma decisão jurídica a respeito dos conflitos que envolvem a garantia dos direitos sociais.

Os juízes não podem simplesmente não decidir. O Poder Judiciário, portanto, deve oferecer uma resposta - dentro do código operativo do Direito - sempre que demandado para solucionar conflitos em torno dos direitos sociais. Desta forma, o poder Judiciário brasileiro, mesmo alicerçado no purismo metodológico, vem enfrentando questões relativas a direitos sociais e proferindo decisões jurídicas acerca do tema. Desta forma, indagamos: como o sistema jurídico garante este direito, no âmbito da microjustiça, sem que traga para o seu âmago as questões relativas às políticas públicas de saúde? É possível a defesa deste direito pelo sistema jurídico, sem que este sistema reconheça internamente os atos administrativos que integram essa política?

A indagação de Lopes é pertinente: "temos visto algumas tentativas de responsabilização do Estado por omissão de serviços essenciais. E, no entanto, tal responsabilização é bastante complexa e difícil, visto que a maioria dos serviços omitidos são uti universi e não uti singuli, não remu-

(53) BUCCI, M. P. D. op. cit., p. 262.

(54) FARIA, J. E. op. cit., p. 94. 
nerados diretamente pelos usuários, mas mantidos por meio de impostos gerais, etc. Além disso, a prestação do serviço depende da real existência dos meios: não existindo escolas, hospitais e servidores capazes e em número suficiente o que fazer? Prestá-lo a quem tiver tido a oportunidade e a sorte de obter uma decisão judicial e abandonar a imensa maioria à fila de espera? Seria isto viável de fato e de direito, se o serviço público deve pautar-se pela sua universalidade, impessoalidade e atendimento a quem dele mais precisar e cronologicamente anteceder os outros.?"(55)

A questão do acesso a medicamentos pela via judicial vem sendo enfrentada, de forma crescente, pelo Judiciário brasileiro, como garantia do direito social à saúde estabelecido na Constituição Federal de 1988(56) (57). E, como evidenciado por Marques, $2005^{(58)}$, a garantia desse direito pelo Poder Judiciário não vem sendo acompanhada das discussões políticas, formalizadas em políticas públicas tendentes a garantir o direito social à assistência farmacêutica para toda a coletividade.

Ou seja, ao garantir o direito à assistência farmacêutica, que geralmente é pleiteado em juízo como um direito público subjetivo, o Judiciário não vem reconhecendo as políticas públicas de assistência farmacêutica, que envolvem a garantia desse direito. E, assim, acaba por proferir uma decisão judicial com base unicamente no arcabouço legal existente, sem considerar a dimensão política tendente a garantir esse mesmo direito para toda coletividade, expressa através das políticas públicas formalizadas em decretos, portarias e resoluções ${ }^{(59)}$.

Assim, as decisões judiciais analisadas em Marques ${ }^{(60)}$ acabaram por "atropelar" a tomada de decisões coletivas em matéria de assistência farmacêutica, desconsiderando a política pública de medicamentos que, inclusive, garante a eficácia e segurança dos medicamentos consumidos pela população brasileira. E, em $90,3 \%$ dos processos analisados, os juízes proferiram decisões que determinam uma atuação específica do Estado, de forma descontextualizada das questões políticas que envolvem o direito social em foco.

Desta forma, o Poder Judiciário proferiu decisões e criou direitos para as partes litigantes, com base exclusivamente no aparato legal que envolve o direito social à assistência farmacêutica. Ou seja, criou esses direitos com

(55) LOPES, J. R. L. op. cit., p. 131.

(56) MARQUES, S. B. A relação do sistema jurídico e do sistema político na garantia do direito social à assistência farmacêutica: o caso do Estado de São Paulo. 2005. (Dissertação apresentada ao Departamento de Prática de Saúde Pública) - Faculdade de Saúde Pública da Universidade de São Paulo, São Paulo, São Paulo, 2005.

(57) Brasil. Conselho Nacional dos Secretários de Saúde. Para entender a gestão do programa de medicamentos de dispensação em caráter excepcional. Brasília, 2004. (CONASS Documenta 3).

(58) MARQUES, S. B. op. cit.

(59) Id. Ibid.

(60) Id. Ibid. 
base na metodologia lógico-dedutiva das normas postas de Kelsen, que não conhece outros elementos dentro do sistema jurídico, que não os estritamente normativos. E, no caso referenciado, o Poder Judiciário considerou apenas, para a utilização desta metodologia, as leis postas pelo Parlamento. Não considerou as normas jurídicas decorrentes dos atos administrativos postos em conformidade com a lei, que compõem a política pública de medicamentos no Brasil.

E, com base nessa metodologia positivista, o Poder Judiciário procurou, em cada caso concreto, encontrar um dever reflexo ao direito à assistência farmacêutica, para proferir a sua decisão jurídica. Todavia, o dever reflexo encontrado nos processos analisados traduziu-se em uma prestação uti singuli por parte do Estado, desvinculada da política pública já estabelecida para garantir este direito social, através de uma prestação uti universi.

De acordo com Amaral, 2001 "o judiciário está aparelhado para decidir casos concretos, lides específicas que lhe são postas. Trata ele, portanto, da microjustiça do caso concreto"(61). Nesse sentido, o Poder Judiciário acabou por individualizar este direito e sobrepor as suas decisões, voltadas para atender interesses e necessidades individuais, às decisões políticas, dirigidas ao direito à assistência farmacêutica de toda a coletividade. E, ao se fechar cognitivamente para os estímulos provenientes do sistema político, expressos juridicamente através dos atos administrativos que compõem a política pública neste âmbito, o Poder Judiciário acabou por desconsiderar, também, os limites estruturais do próprio sistema jurídico.

Em última instância, a decisão judicial acabou por influir na tomada de decisões coletivas em matéria de assistência farmacêutica, função que não é específica do sistema jurídico. Ao determinar juridicamente uma atuação do Estado, sem considerar a política pública trazida aos autos, as decisões judiciais acabaram por influir na própria tomada de decisões coletivas pelo sistema político, determinando quem atender, quais medicamentos específicos fornecer e em que tempo.

Assim, o sistema jurídico passa a atuar para além de suas fronteiras estruturais e determinar a tomada de decisões coletivas pelo sistema político, impedindo, assim, que o sistema político opere autopoieticamente para proferir essas decisões, com base em suas operações internas e código específico de comunicação. Passa a perseguir, desta forma, finalidades políticas, evidenciando-se o problema da "judicialização" da política de assistência farmacêutica no Estado de São Paulo(62).

(61) AMARAL, G. op. cit., p. 38.

(62) Cf. CAMPILONGO, C. F. op. cit. e NEVES, M. C. P. op. cit. A doutrina aponta que, caso haja confusão acerca do papel do direito e da política, esses sistemas podem atuar de forma não condizente com as suas operações internas e especificidades funcionais, perseguindo finalidades que não são próprias de seu sistema. E isso pode acarretar problemas como a "judicialização da política" ou a "politização do direito". 
O código de comunicação do sistema jurídico só está apto para oferecer respostas dentro do binômio direito/não direito. Somente com base no processamento interno dos atos jurídicos que compõem a política pública de assistência farmacêutica, o sistema jurídico revela-se capacitado para proferir uma resposta jurídica acerca desta política e, assim, com base na legalidade/ilegalidade dos atos desta política, determinar comportamento diverso por parte da administração pública. E, de acordo com a teoria dos sistemas autopoiéticos, quando um sistema passa a perseguir uma finalidade que não é a sua específica, determinando as operações internas de outro sistema, ocorrem prejuízos para a estabilidade da sociedade diferenciada funcionalmente, para a manutenção da complexidade e da contingência no interior dos sistemas e para a própria democracia.

De acordo com Campilongo, 2000(63), a democracia constitucional pressupõe a separação entre os sistemas político e jurídico, cada qual perseguindo a sua função específica. Assim, a "judicialização da política" e a sobreposição das decisões judiciais e do arcabouço normativo às opções políticas, representam uma ameaça à própria. democracia e à complexidade interna desses sistemas.

Zaffaroni sustenta que "não há outra forma de salvar a organicidade legislativa além de um trabalho de elaboração judicial coerente, não só quanto à lógica interna do discurso jurídico, como também no que toca a sua lógica política. A falta de um poder judiciário capaz de executar essa tarefa pode provocar insegurança jurídica grave, com conseqüente perigo para a democracia"(64).

Desta forma, é fundamental, para o próprio equilíbrio democrático, que o sistema jurídico reconheça os estímulos políticos que envolvem a garantia do direito à assistência farmacêutica, e atue dentro de seus limites estruturais, perseguindo a sua função específica de garantir às expectativas normativas. Com a "judicialização" da política de assistência farmacêutica, o sistema jurídico e o político confundem suas funções e operações específicas na defesa do direito à assistência farmacêutica, o que prejudica o equilíbrio da sociedade diferenciada funcionalmente e, em última instância, a própria democracia.

Amaral, 2001(65), sustenta que a decisão judicial, nesses moldes, é uma decisão alocativa de recursos em saúde. Mesmo que não se reconheça como tal, a decisão judicial extrapola os limites estruturais do sistema jurí-

(63) CAMPILONGO, C. F. O direito na sociedade complexa, cit.

(64) ZAFFARONI, E. R. Estructuras judiciales. Buenos Aires: Ediar, 1994. p. 28.

(65) AMARAL, G. Direitos, escassez \& escolha: em busca de critérios jurídicos para lidar com a escassez de recursos e as decisões trágicas, cit. 
dico e determina, por fim, como devem ser gastos determinados recursos da política de assistência farmacêutica. $E$ tais recursos, como é sabido, são públicos e escassos, que demandam critérios claros e equânimes de alocação. E o sistema político, pela especificidade de sua função e de seu aparato operacional, é mais capacitado para alocar esses recursos escassos e estabelecer tais critérios.

Assim, no âmbito da saúde, a insuficiência de recursos revela-se demasiadamente preocupante, pois não se pode conferir, a todos os cidadãos brasileiros, todas as possibilidades terapêuticas de que venham a necessitar. Por isso, a alocação de recursos em saúde, de forma a melhor atender às necessidades de toda a população, revela-se indispensável para que se possa promover efetivamente uma justiça distributiva e eqüitativa de cuidados com a saúde. E esta função, como já dito, não é capaz de ser cumprida pelo sistema jurídico.

Destaca-se que, na pesquisa referida(66), $100 \%$ dos autores eram autores individuais ou em litisconsorte ativo, referente a - no máximo cinco indivíduos. Este fato reforça a idéia de que a prestação judicial inserese, por sua própria natureza, no âmbito da justiça comutativa ${ }^{(67)}$.

Neste contexto, a preocupação de Dallari é relevante: "É preciso ter muito claro, entretanto, que para a real proteção judicial dos direitos humanos não é suficiente e, pelo contrário, é perigoso só cumprir as formalidades judiciárias, ter uma aparência de proteção judicial, que adormece a vigilância e que não é, porém, mais do que uma ilusão de justiça". ${ }^{(68)}$

Nas sociedades periféricas, como a brasileira, o perigo da "judicialização" da política é ainda mais relevante, pois o acesso à justiça é restrito a uma pequena parcela da população. E, assim, o problema da "corrupção" de códigos e da tomada de decisões coletivamente vinculantes, com base em casos individualizados, torna-se ainda mais preocupante.

Esta individualização da prestação coletiva pode levar a favorecimentos individuais, em detrimento dos interesses de uma coletividade que não se faz representar em juízo. Assim, a alocação de recursos para atender os casos que chegam ao Judiciário prejudica a alocação de recursos e o estabelecimento de prioridades, pelo sistema político, com base em critérios

(66) MARQUES, S. B. op. cit.

(67) AMARAL, G. Direitos, escassez \& escolha. em busca de critérios jurídicos para lidar com a escassez de recursos e as decisões trágicas, cit., sustenta que "diante de um quadro como esse, a tendência é fugir do problema, negá-lo. Esse processo é bastante fácil nos meios judiciais. Basta observar apenas o caso concreto posto nos autos. Tomada individualmente, não há situação para a qual não haja recursos. Não há tratamento que suplante o orçamento da saúde ou, mais ainda, os orçamentos da União, de cada um dos Estados, do Distrito Federal ou da grande maioria dos municípios. Assim, enfocando apenas o caso individual, vislumbrando apenas o custo de cinco mil reais por mês para um coquetel de remédios, ou de cento e setenta mil para um tratamento no exterior, não se vê a escassez do recurso" (p.146-147).

(68) DALLARI, D. A. O poder dos juízes, cit., p. 38. 
globais. E, desta forma, prejudica aqueles que não têm acesso à informação e não conseguem "chegar" até o Judiciário.

De acordo com Santos "o tema do acesso à justiça é aquele que mais directamente equaciona as relações entre o processo civil e a justiça social, entre igualdade jurídico-formal e desigualdade sócio-económica"(sic) ${ }^{(69)}$. Destaca-se que, na referida pesquisa, verificou-se que $67,7 \%$ dos autores chegaram ao Judiciário através da representação de advogados particulares e, destes autores, $23,8 \%$ possuíam o apoio de associações específicas, criadas para proteger interesses de portadores de determinada patologia, ou interesses relacionados à saúde de modo geral.

Desta forma, mais da metade dos autores dos processos estudados fazem parte de uma minoria da população brasileira, que possui condições sociais, culturais e financeiras para contratarem a representação de um advogado particular. De acordo com Santos, "quanto mais baixo é o estrato sócio-económico(sic) do cidadão, menos provável que conheça advogado ou que tenha amigos que conheçam advogados, menos provável que saiba onde, como e quando pode contactar um advogado e maior é a distância geográfica entre o lugar aonde vive ou trabalha e a zona da cidade onde se encontram os escritórios de advocacia e os tribunais"(70).

Assim, reforça-se a idéia de que a microjustiça do caso concreto pode levar à tomada de decisões coletivas, com foco em interesses individuais e de determinados grupos organizados. O sistema político, como já ressaltado, é mais apto a tomar decisões coletivas em saúde com foco em critérios globais, planejando e justificando tais critérios, com base nas necessidades coletivas. E, também, é mais apto para lidar com as pressões de grupos sociais e econômicos, periféricos ao sistema político, que tencionam e procuram influir na tomada de decisões coletivas.

Não se defende aqui que as necessidades individuais não devam ser atendidas e que o Estado possa ser negligente frente a indivíduos que correm iminente risco de vida. No entanto, como o direito à assistência farmacêutica depende de uma política pública e de recursos públicos para ser garantido, sob a perspectiva da justiça distributiva, é preciso que essas necessidades individuais sejam contextualizadas dentro da política pública de medicamentos. Assim, a noção de justiça distributiva pode nortear a prestação coletiva e o próprio atendimento às necessidades terapêuticas individuais.

(69) SANTOS, B. S. A sociologia dos tribunais e a democratização da justiça. In: . Pela mão de Alice: o social e o político na pós-modernidade. 9. ed. São Paulo: Cortez, 2003. p. $\overline{167 . ~ O}$ autor continua sustentando que "estudos revelam que a distância dos cidadãos em relação à administração da justiça é tanto maior quanto mais baixo é o estrato social a que pertencem e que essa distância tem como causas mais próximas não apenas factores económicos, mas também factores sociais e culturais (...) Em primeiro lugar, os cidadãos de menores recursos tendem a conhecer pior os seus direitos e, portanto, a ter mais dificuldades em reconhecer um problema que os afecta como sendo problema jurídico" (p. 170).

(70) SANTOS, B. S. op. cit., p. 170. 
Concluímos que existem muitas dificuldades em relação à garantia efetiva dos direitos sociais no Brasil, principalmente no que tange ao seu processamento interno pelo sistema jurídico. Por se tratar de direitos que dependem de uma atuação positiva do Estado para serem implementados, e se referem a uma coletividade, esses direitos extrapolam o paradigma positivista da proteção de interesses e liberdades individuais, sobre o qual se funda o Estado moderno de direito e o sistema jurídico moderno. E, assim, reclamam um outro olhar e um outro tratamento por parte dos aplicadores do Direito, no sentido de uma justiça efetivamente distributiva, da qual todos nós, cidadãos brasileiros, somos tão carentes.

\section{REFERENCIAS}

AMARAL, G. Direitos, escassez \& escolha: em busca de critérios jurídicos para lidar com a escassez de recursos e as decisões trágicas. Rio de Janeiro: Renovar, 2001.

- Interpretação dos direitos fundamentais e o conflito entre poderes. In:Torres, R.L (Org.). Teoria dos direitos fundamentais. 2. ed. Rio de Janeiro: Renovar, 2001. p. 99-120.

AZEVEDO, P. F. Direito, justiça social e neoliberalismo. São Paulo: Ed. Revista dos Tribunais, 2000.

BRASIL. Conselho Nacional dos Secretários de Saúde. Para entender a gestão do programa de medicamentos de dispensação em caráter excepcional. Brasília, 2004. (CONASS Documenta 3).

BUCCI, M. P. D. Direito administrativo e políticas públicas. São Paulo: Saraiva, 2002.

CAMPILONGO, C. F. O direito na sociedade complexa. São Paulo: Max Limonad, 2000.

2002.

. Política, sistema jurídico e decisão judicial. São Paulo: Max Limonad,

COELHO, P. M. C. Controle jurisdicional da administração pública. São Paulo: Saraiva, 2002.

COMPARATO, F. K. Fundamento dos direitos humanos. In: Marcílio, M. L., Pussoli, L. Cultura dos direitos humanos. São Paulo: LTr, 1998. p. 51-74.

DALLARI, D. A. Elementos de teoria geral do Estado. 23. ed. São Paulo: Saraiva, 2002. . O poder dos juízes. 2. ed. São Paulo: Saraiva, 2002.

DALLARI, S. G. Os estados brasileiros e o direito à saúde. São Paulo: Hucitec, 1995. 
DIÁZ, E. Sociología y filosofia del derecho. Madrid: Tauru, 1976.

FARIA, J. E. O Judiciário e os direitos humanos e sociais: notas para uma avaliação da justiça brasileira. In: (Org.). Direitos humanos, direitos sociais e justiça. São Paulo: Malheiros Ed., 2002. p. 94-112.

KELSEN, H. Teoria pura do direito. 6. ed. São Paulo: Martins Fontes, 1998.

KUNTZ, R. Estado, mercado e direitos. In: FARIA, J. E.; KUNTZ, R. Qual o futuro dos direitos? Estado, mercado e justiça na reestruturação capitalista. São Paulo: Max Limonad, 2002.

LOPES, J. R. L. Direito subjetivo e direitos sociais: o dilema do judiciário no estado social de direito. In: FARIA, J. E. (Org). Direitos humanos, direitos sociais e justiça. São Paulo: Malheiros Ed., 2002. p. 113-143.

LUHMANN, N. Sociologia do direito. Rio de Janeiro: Tempo Brasileiro, 1983.

MARQUES, S. B. A relação do sistema jurídico e do sistema político na garantia do direito social à assistência farmacêutica: o caso do Estado de São Paulo. 2005. Dissertação (Mestrado - Prática de Saúde Pública) Faculdade de Saúde Pública, Universidade de São Paulo, São Paulo, São Paulo, 2005.

MARSHALL, T. H. Cidadania, classe social e status. Rio de Janeiro: Zahar, 1967.

MATHIS, A. O conceito de sociedade na teoria dos sistemas de Niklas Luhmann. Rebea 2002 [texto doutrina]; [18 screens]. Disponível em: <www.rebea. org.br/rebea/arquivos/niklas.pdf>. Acesso em: 30.jan.2005.

NEVES, M. C. P. Entre Têmis e Leviatấ: uma relação difícil. 1997. Tese (Titular do Departamento de Filosofia e Teoria Geral do Direito) - Faculdade de Direito, Universidade de São Paulo, São Paulo, 1997.

SANTOS, B. S. A sociologia dos tribunais e a democratização da justiça. In: . Pela mão de Alice: o social e o político na pós-modernidade. 9. ed. São Paulo: Cortez, 2003.

ZAFFARONI, E. R. Estructuras judiciales. Buenos Aires: Ediar, 1994. 